\title{
The Effects of Sintering Temperature on Densification and Mechanical Properties of Hydroxyapatite/Sodium Alginate Biocomposites
}

\author{
Nanthini Kanasan ${ }^{1,}$, Sharifah Adzila1,, , Nor Azimah Mustaffa ${ }^{1}$, Sabriy Mad Sidi $^{1}$, Mohd \\ Nasrull Abdol Rahman ${ }^{1}$, N. F. Nasir ${ }^{1}$, and P. Gurubaran ${ }^{2}$ \\ ${ }^{1}$ Faculty of Mechanical and Manufacturing Engineering, Universiti Tun Hussein Onn Malaysia, \\ Johor, Malaysia, \\ ${ }^{2}$ School of Mechatronic Engineering, Universiti Malaysia Perlis, Pauh Putra Campus, Arau, Perlis, \\ Malaysia,
}

\begin{abstract}
Hydroxyapatite (HA) has been studied for their excellent performances which are suitable for use in bone defects or regeneration of bone. Hydroxyapatite (HA) has poor mechanical properties which make it limited used in a load bearing area. In this case, sodium alginate (SA) was used to be mixed with hydroxyapatite (HA) by using precipitation method to increase the mechanical and physical properties. The mixing of hydroxyapatite/sodium alginate effectively increases the densification and hardness of hydroxyapatite. It could contribute to the development of the artificial implants of hydroxyapatite (HA) for bone implants applications in load bearing area. The behaviors during densification were studied together with the mechanical properties of samples. The influence of mixed powder and the sintering temperature on densification, microstructure and mechanical properties of hydroxyapatite (HA)/sodium alginate (SA) composite were studied. The maximum density were attained by $99.5 / 0.5 \%$ $(\mathrm{HA} / \mathrm{SA})$ at $1.47 \mathrm{~g} / \mathrm{cm} 3$ and $1.82 \mathrm{~g} / \mathrm{cm} 3$ for both temperature $1000^{\circ} \mathrm{C}$ and $1100^{\circ} \mathrm{C}$ respectively while, the maximum values of hardness were also attained by $99.5 / 0.5 \%$ for temperature $1000^{\circ} \mathrm{C}$ and $1100^{\circ} \mathrm{C}$ at $0.053 \mathrm{GPa}$ and $0.266 \mathrm{GPa}$ respectively.
\end{abstract}

\section{Introduction}

Hydroxyapatite (HA) $\left(\mathrm{Ca}_{10}\left(\mathrm{PO}_{4}\right)_{6}(\mathrm{OH})_{2}\right.$ is the inorganic component of bones that have excellent biocompatibility with a lot of application in biomedical fields and act as filler due to its characteristics. These are similar to mineral component that present in bones and hard tissues [1]. The combination of ceramic based materials such as hydroxyapatite and natural polymer as sodium alginate will provide strength, stiffness and fracture toughness to the 
bone $[2,3]$.The composite materials have been used in load bearing application such as filler and bone defect.

Alginate (Alg) is a natural polymer which synthesized from brown algae. Alginate is more prefer to be used due to its biocompatibility, low cost and low toxicity. In this work, sodium alginates (SA) were used to improve the physical and mechanical properties of ceramic materials. Sodium alginate act as a hydrophilic and it can be dissolved in water but not entirely soluble [1].

The powder properties of hydroxyapatite are depends on the processing method and sintering temperature. This is important to improve the performance such as powder morphology and distribution of particles size. Several studies shows that, the porosity of composites are decrease by adding sodium alginate on hydroxyapatite [4,5]. The densifications of hydroxyapatite are varies based on the powder characteristics where the carbonate content improved the densification of hydroxyapatite and sintering which are performed at a temperature lower than $1250^{\circ} \mathrm{C}$ to avoid the loss carbonate content [6]. Usually densifications are achieved by compaction and sintering method. The physical and mechanical properties can be improved by controlling the particle size and shape, the distribution of particles and agglomeration of powder [7]. In this work, HA and HA/SA were sintered at $1000^{\circ} \mathrm{C}$ and $1100^{\circ} \mathrm{C}$ for $2^{\circ} \mathrm{C} / \mathrm{min}$ at heating and cooling rate with 2 hour soaking time. The structural and physical- mechanical properties of HA/SA are investigated.

The aim of this research is to identify the influence of mixed powder and sintering temperature on densification, microstructure and mechanical properties and to characterize the synthesized HA and HA/SA powder by using Field Emission Scanning Electron Microscope (FESEM). The material used is based on calcium phosphate group which is hydroxyapatite and also a natural polymer as sodium alginate. Since, it is the most common composite material that are suitable to be used in medical application due to it performances for regeneration of bone implants. The biomedical application of HA and sodium alginate were studied in term of behaviors, microstructure, densification and mechanical properties.

\section{Experimental Method}

The commercial HA nano powder $\mathrm{Ca}_{10}\left(\mathrm{PO}_{4}\right)_{6}(\mathrm{OH})_{2}$ and sodium alginate $\mathrm{NaC}_{6} \mathrm{H}_{7} \mathrm{O}$ were obtained from Q-Rec. The sample ratio is $100 / 0 \%, 99.5 / 0.5 \%, 97 / 3 \%, 95 / 5 \%, 92 / 8 \%$ and 90/10\% (HA/SA).

Hydroxyapatite/sodium alginate (HA/SA) powder was prepared by using precipitation method. The mixed powders are sintered at two different temperatures from $1000^{\circ} \mathrm{C}$ to $1100^{\circ} \mathrm{C}$. The mixing process was carried out by using hot plate and magnetic stirrer. The pure hydroxyapatites were mixed with distilled water and sodium alginate was put into the solution. The suspension powder was left overnight to get the precipitate solution. Next, the precipitation solutions were dried at 24 hours in $80^{\circ} \mathrm{C}$.

Then, the dried sample was crushed and sieved to obtain the fine powders. 1 grams of mixed powder are compacted at $2.5 \mathrm{MPa}$ load by using stainless steel mould $(13 \mathrm{~mm})$. The mould should be clean by using WD40 or silicon spray which act as a lubricant to remove dirt and to remove the sample easily after compaction. The compacted samples were sintered at $1000^{\circ} \mathrm{C}$ and $1100^{\circ} \mathrm{C}$ in soaking time 2 hours with $2^{\circ} \mathrm{C} / \mathrm{min}$ of heating and cooling rates. Next, the bulk density of sintered samples were measured based on the Archimedes principle by using Mettler Toledo Densitometer. The sintered samples were grinded by using $\mathrm{SiC}$ paper (600-1000 grit) and polished by using diamond paste suspension. 
For each composition, 10 indentations were made by using pyramidal diamond indenter (HMV,Shimadzu) for 10 seconds under $0.2 \mathrm{HV}$. Thermal etched was done at $950^{\circ} \mathrm{C}$ and $1050^{\circ} \mathrm{C}$ in 30 minutes with $2^{\circ} \mathrm{C} / \mathrm{min}$ of heating and cooling rates. The etched surface sample is coated with gold before characterized under Field Emission Scanning Electron Microscopy (FESEM).

\section{Results and Discussion}

\subsection{Characterization of nanoparticles}

The FESEM microstructure of $\mathrm{HA}$ and HA/SA sintered samples are analyzed at temperature about $1000^{\circ} \mathrm{C}$ and $1100^{\circ} \mathrm{C}$ as shown in Figure 1 (a) and 1 (b). The particle size growth slowly as the sintering temperature increases from $1000^{\circ} \mathrm{C}$ to $1100^{\circ} \mathrm{C}$ and the particles size was in irregular shapes. The particles size for $1000^{\circ} \mathrm{C}$ to $1100^{\circ} \mathrm{C}$ were increased due to the increase in percentage of sodium alginate (SA) while the porosity was decreased. The morphology of $1100^{\circ} \mathrm{C}$ shows the microstructures of grains are more compact, dense and has an irregular shape. The HA nanoparticle exhibit irregular shape with a grain size below $137 \mathrm{~nm}$. The different particles size and shape would affect the bonding between each other which it influence the efficiency of regeneration process. HA particle were fully dispersed through the SA. HA was not identify individually due to the fully covered of SA into HA which make a complete composite materials. Composite occur due to the interaction between hydroxyl and carboxyl of HA and SA. The reasons for this are related to strong ionic interactions between the alginate and $\mathrm{Ca}^{2+}$ content into $\mathrm{HA}$ structure. This study is similar to Choi and Kumta 2006, whereby the interaction between the alginate and carbonate content incorporated into hydroxyapatite structure [8].The rapid growth of HA and HA/SA particle size were observed in Figure 1 (a) and 1 (b) for $1000^{\circ} \mathrm{C}$ and $1100^{\circ} \mathrm{C}$. The microstructure of $1000^{\circ} \mathrm{C}$ shows that there are interconnected pores appear in the $\mathrm{HA}$ and $\mathrm{HA} / \mathrm{SA}$ composite material while, for $1100^{\circ} \mathrm{C}$ the pores were decreased according to the increase in sintering temperature. The microstructure shows the better distribution of hydroxyapatite (HA) into the polymer reinforcement composite with good porosity that are required in growth of bone in implants process. Small spherical and irregular particles are observed in the agglomerates microstructure of hydroxyapatite (HA) and hydroxyapatite/sodium alginate (HA/SA). The percentages of porosity were affected when there is any changes in sintering temperature. The porosity will give the result to the decrease of strength in bone implants. The higher sintering temperature can control the microporosity of biocomposite materials. Nag et al., 2012 said that, the decrease of porosity resulting effect to the strength of implant materials drastically could bring challenge for load-bearing implants [9]. The comparison of HA and HA/SA sinter samples shows that the $1100^{\circ} \mathrm{C}$ have less porosity if compare with $1000^{\circ} \mathrm{C}$. In comparison of particles size for sintering temperature of $1000^{\circ} \mathrm{C}$ were in the range of $0.26-0.72 \mu \mathrm{m}$ at ratio $100 / 0 \%$, $99.5 / 0.5 \%, 97 / 3 \%, 95 / 5 \%, 92 / 8 \%$ and $90 / 10 \%$. The temperature at $1100{ }^{\circ} \mathrm{C}$ the size range is about $0.72-1.26 \mu \mathrm{m}$ at ratio $100 \%, 99.5 / 0.5 \%, 97 / 3 \%, 95 / 5 \%, 92 / 8 \%$ and $90 / 10 \%$.It conclude that the ceramic-polymer experience problem due to aggregation of ceramic particles due to lack of bonding strength and faced difficulty in the intermixing of hydrophilic ceramic particle with hydrophobic polymer. Other than that, the mixing process and precipitation condition also influence the particle size where for $92 \%$ and $90 \%$ of HA faced some decrease in particle sizes. The results for $95 / 5 \% \mathrm{HA} / \mathrm{SA}$ for $1100^{\circ} \mathrm{C}$, a lot of small size particles compared to other composition are due to high coating process. 


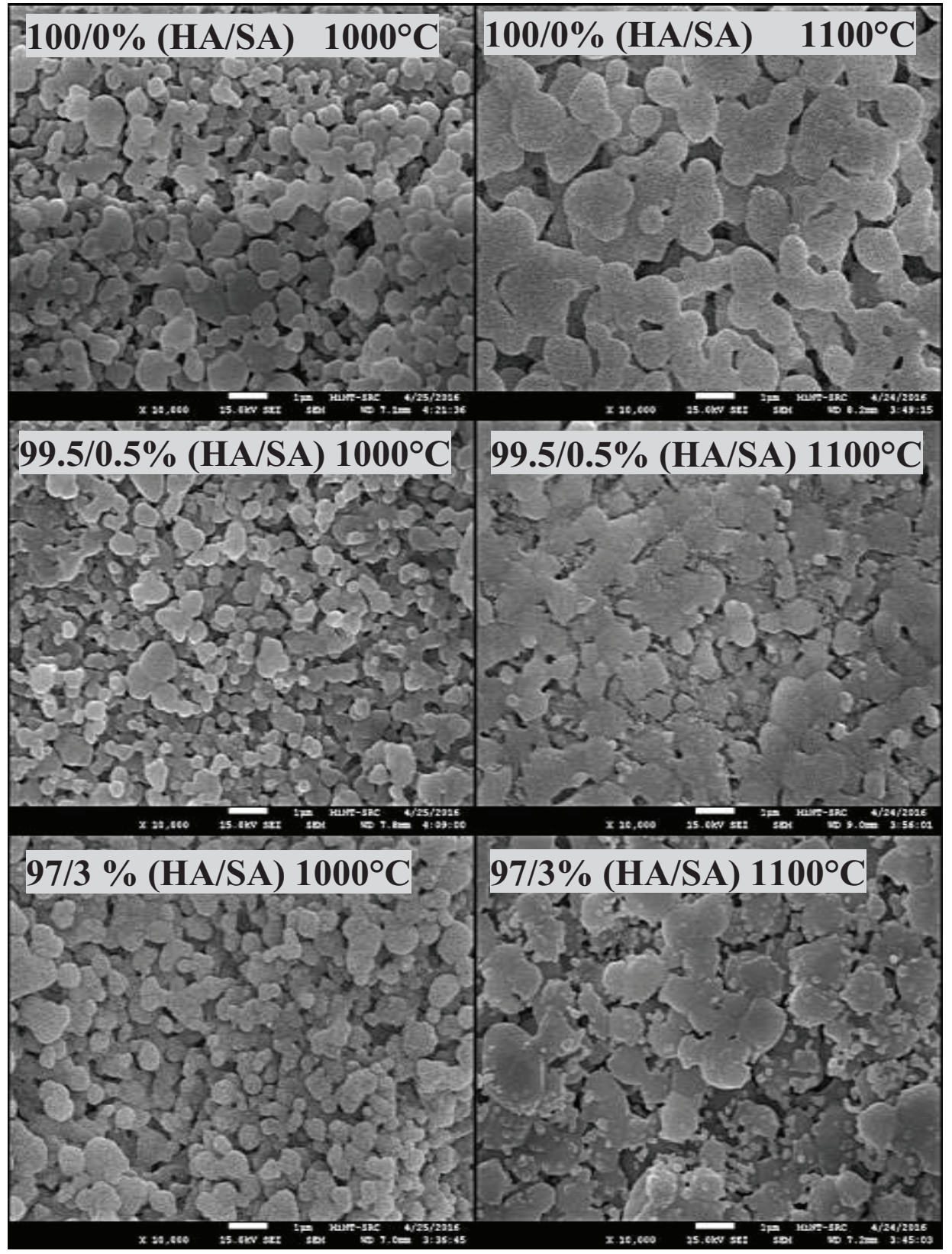

Fig.1. (a) FESEM of HA and HA/SA at ratio composition about $100 / 0 \%, 99.5 / 0.5 \%$ and $97 / 3 \%$ shows the variety in crystal shape and size at about $1000^{\circ} \mathrm{C}$ and $1100^{\circ} \mathrm{C}$ of sintering temperature. 


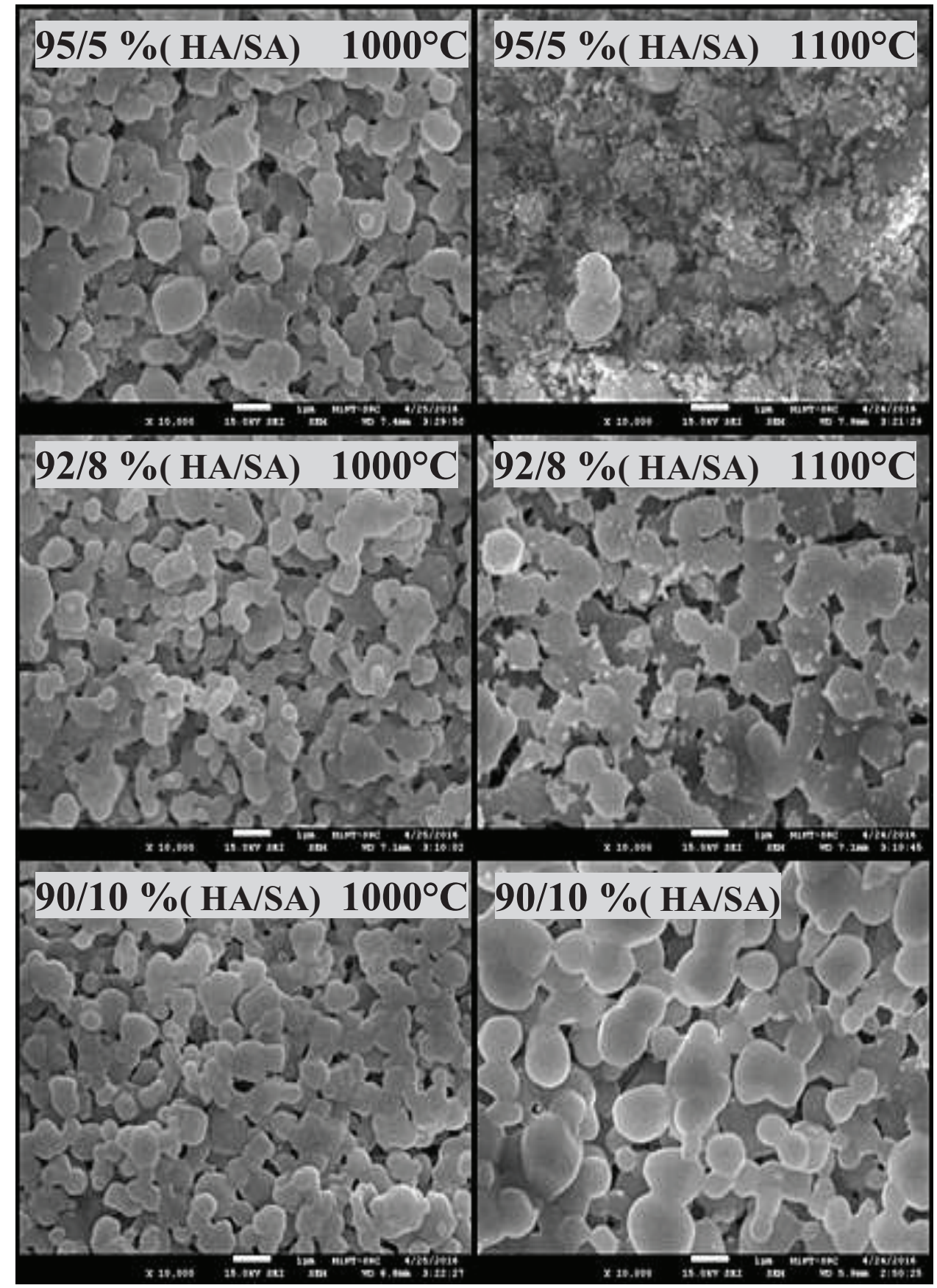

Fig. 1. (b) FESEM of HA and HA/SA at various ratio such as $95 / 5 \%, 92 / 8 \%$ and $90 / 10 \%$ shows the variety in crystal shape and size at about $1000^{\circ} \mathrm{C}$ and $1100^{\circ} \mathrm{C}$ of sintering temperature. 


\subsection{Densification}

The density tests are measure based on Archimedes principle. The densification for sintered HA and HA/SA sample are varies according to ratio composition are shown in Figure 2. The sintering temperatures are further increased by reduction of porosity and this resulting the rapid growth of $\mathrm{HA}$ particle size. The sintering temperature at $1000^{\circ} \mathrm{C}$ with ratio concentration of $100 / 0 \%, 99.5 / 0.5 \%$ (HA/SA) shows the densification was increased from $1.44 \mathrm{~g} / \mathrm{cm}^{3}$ to $1.47 \mathrm{~g} / \mathrm{cm}^{3}$ and $1.8 \mathrm{~g} / \mathrm{cm}^{3}$ to $1.82 \mathrm{~g} / \mathrm{cm}^{3}$ for $1000^{\circ} \mathrm{C}$ and $1100^{\circ} \mathrm{C}$ each respectively. The maximum density are attained at $99.5 / 0.5 \%(\mathrm{HA} / \mathrm{SA})$ about $1.47 \mathrm{~g} / \mathrm{cm}^{3}$ and $1.82 \mathrm{~g} / \mathrm{cm}^{3}$ for both $1000^{\circ} \mathrm{C}$ and $1100^{\circ} \mathrm{C}$ sintering temperature. It summaries that, HA are found to have a good compact structure at this composition. Further increase in the amount of sodium alginate (SA) decrease the density of samples. Then, the ratio concentration of sodium alginate (SA) at $1000^{\circ} \mathrm{C}$ for $5 \%, 8 \%$ and $10 \%$ were decreased at about $1.42 \mathrm{~g} / \mathrm{cm}^{3}, 1.28 \mathrm{~g} / \mathrm{cm}^{3}$ and $1.25 \mathrm{~g} / \mathrm{cm}^{3}$ respectively while, for $1100^{\circ} \mathrm{C}$ at $1.70 \mathrm{~g} / \mathrm{cm}^{3}$, $1.55 \mathrm{~g} / \mathrm{cm}^{3}$ and $1.55 \mathrm{~g} / \mathrm{cm}^{3}$. According to the previous results shows by Rajkumar, Meenakshisundaram, and Rajendran 2011, the increase in the amount of sodium alginate (SA) will decrease the density of samples [10]. The trends was unstable at 97/3\% (HA/SA) where there is a slight decrement in value of $1.31 \mathrm{~g} / \mathrm{cm}^{3}$ and $1.56 \mathrm{~g} / \mathrm{cm}^{3}$ for $1000^{\circ} \mathrm{C}$ and $1100^{\circ} \mathrm{C}$

respectively.

\subsection{Vickers Hardness}

The mechanical properties of composites material are important due to which it act as a physical support for the regeneration of bone implants. Sodium alginate are prepared with hydroxyapatite to form a composites materials to achieve a certain mechanical properties. Figure 3 shows the Vickers hardness of sintered sample at various ratio concentrations. The hardness of hydroxyapatite (HA) and hydroxyapatite/sodium alginate (HA/SA) increased with an increase in sintering temperature. The increase of hardness with the increase of sodium alginate (SA) was observed up to $99.5 / 0.5 \%$, whereas there were decrement of hardness values noticeable with further increase in SA. The increase in hardness happen due to the interaction between calcium ions and SA to form a strong matrix structures while, the decrease happen due to polymer that are broken when act by external forces. This finding are similar to Rajkumar, Meenakshisundaram, and Rajendran 2011 [10]. The maximum hardness is observed at $99.5 / 0.5 \%(\mathrm{HA} / \mathrm{SA})$ as $0.053 \mathrm{GPa}$ and $0.266 \mathrm{GPa}$ for $1000^{\circ} \mathrm{C}$ and $1100^{\circ} \mathrm{C}$ respectively by which it indicates that the sintering temperature has an influence the hardness of sample. The particles size are closely packed to form dense materials when there is a higher sintering occurred and this is the reason for increase in hardness. 


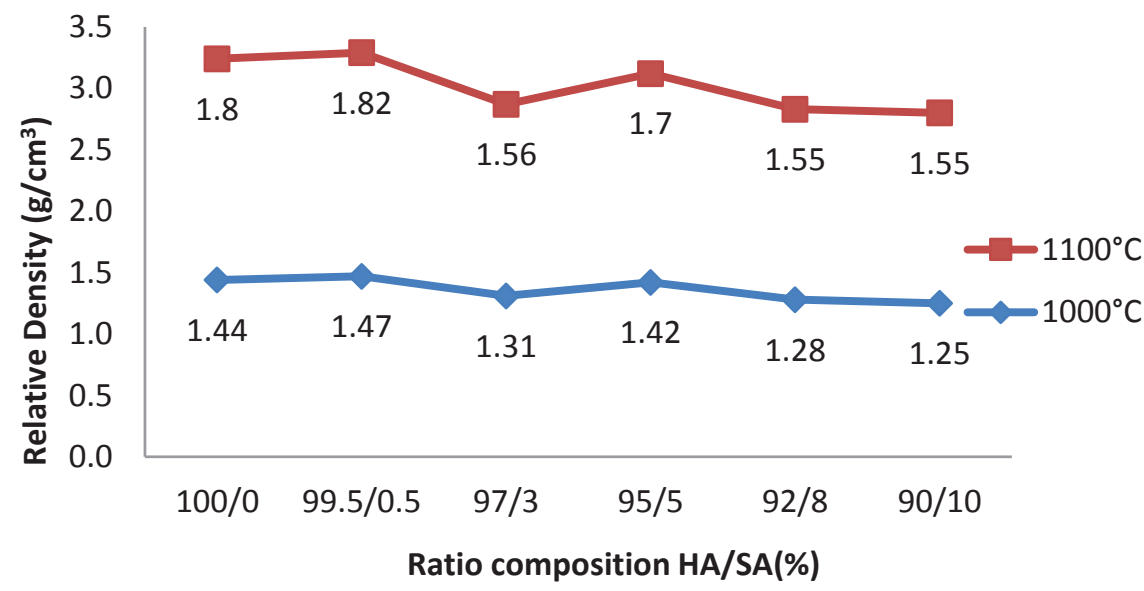

Fig. 2. Density (g/cm3) versus ratio composition of HA and HA/SA

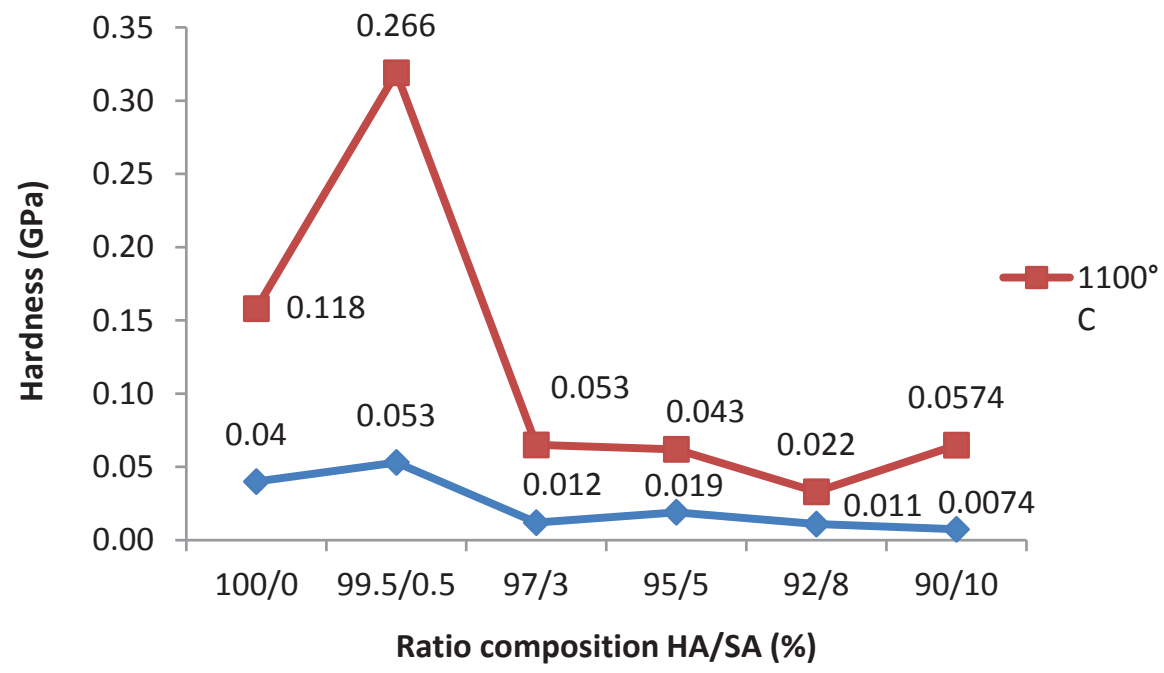

Fig. 3. Hardness (GPa) versus ratio composition of HA and HA/SA

\section{Conclusions}

In this work, the composite materials are investigated based on two precursors which are hydroxyapatite and sodium alginate. The parameter used are varies according to ratio composition between hydroxyapatite and sodium alginate. The HA and HA/SA composites sample shows that the sintering temperature have significant effect on the densification and mechanical properties. By characterization of HA and HA/SA composites, it indicates that the sintering temperatures has effect on the microstructure of composite materials. The FESEM analysis shows the distribution size of irregular and spherical particle was very close and no contamination happen. The maximum density were attained by $99.5 / 0.5 \%$ 
(HA/SA) at $1.47 \mathrm{~g} / \mathrm{cm}^{3}$ and $1.82 \mathrm{~g} / \mathrm{cm}^{3}$ for both temperature $1000^{\circ} \mathrm{C}$ and $1100^{\circ} \mathrm{C}$ respectively while, the maximum values of hardness were also attained by $99.5 / 0.5 \%$ for temperature $1000^{\circ} \mathrm{C}$ and $1100^{\circ} \mathrm{C}$ at $0.053 \mathrm{GPa}$ and $0.266 \mathrm{GPa}$ respectively. The maximum hardness obtained were linearly similar with the density at 99.5/0.5\% (HA/SA) at both sintering temperature. It indicates that hardness was influenced by densification. Higher density and hardness are usually controlled by bonding among the grains of sintered samples. The increase in densification and mechanical properties are promising and offer the potential biomaterials to be used in biomedical applications especially for bone tissues regeneration. Density and hardness play an important role where the behaviours of strength, ductility and toughness are investigated to identify the suitable materials to be used for bone implants.

\section{Acknowledgement}

This study was supported under the Short Termed Grant (STG), Vot number U124. The authors gratefully acknowledge the Office for Research, Innovation, Commercialization and Consultancy Management (ORICC), Universiti Tun Hussein Onn Malaysia and Centre Graduate of Study (UTHM).

\section{References}

1. A. Ilie, C. Ghiţulică, E. Andronescu, A. Cucuruz, and A. Ficai, New Composite Materials Based on Alginate and Hydroxyapatite As Potential Carriers for Ascorbic Acid., Int. J. Pharm. (2016)

2. S. Lala, M. Ghosh, P. K. Das, D. Das, T. Kar, S. K. Pradhan S., Magnesium Substitution in Carbonated Hydroxyapatite: Structural and Microstructural Characterization by Rietveld's Refinement., Materials Chemistry and Physics.170, 319-29(2016)

3. S. Adzila, I. Sopyan, R. Singh, E. Pusparini, M. Hamdi, Mechanochemical synthesis of sodium doped hydroxyapatite powder.,Indian Journal Of Chemistry.52A , 739743(2013)

4. Thangamani, Nithyanantham, K. Chinnakali, and F. D. Gnanam, The Effect of Powder Processing on Densification, Microstructure and Mechanical Properties of Hydroxyapatite., Ceramics International. 28(4), 355-62 (2002)

5. A. Dubnika, D. Loca, L. Berzina-Cimdina, Functionalized Hydroxyapatite Scaffolds Coated with Sodium Alginate and Chitosan for Controlled Drug Delivery., Proceedings of the Estonian Academy of Sciences. 61(3), 193(2012)

6. E. Landi, A. Tampieri, G. Celotti, R. Langenati, M. Sandri, S. Sprio, Nucleation of Biomimetic Apatite in Synthetic Body Fluids: Dense and Porous Scaffold Development., Biomaterials. 26(16), 2835-45(2005)

7. G. Muralithran, S. Ramesh, The Effects of Sintering Temperature on the Properties of Hydroxyapatite., Ceramics International. 26, 221-230(2000)

8. Choi, Daiwon, P. N. Kumta, An Alternative Chemical Route for the Synthesis and Thermal Stability of Chemically Enriched Hydroxyapatite., Journal of the American Ceramic Society. 89(2), 444-49(2006)

9. S. Nag, R. Banerjee, "Materials for medical devices, fundamentals of medical implant materials," ASM Handb., vol. 23, pp. 6-16 (2012)

10. M. Rajkumar, N. Meenakshisundaram, V. Rajendran, Development of Nanocomposites Based on Hydroxyapatite/sodium Alginate: Synthesis and Characterisation., Materials Characterization. 62(5), 469-79 (2011) 